After further thought I hope your correspondent will see fit to publish an apology to those of his profession he has unfairly criticized in his letter-to those who, on graduation, also accepted the Hippocratic Oath and who, along with himself, do their best to adhere to its content.-I am, etc.,

FRED J. ROBERTSON.

Newcastle upon Tyne.

SIR,-I was interested to read Dr. J. W. Todd's letter (28 December, p. 833) concerning the patient who failed to obtain employment in a certain job because of a questionably high blood pressure. At a time when the value of pre-employment medical examinations is being reappraised it is worth bearing in mind two aspects of work-placement in which a knowledge of the applicant's medical history and clinical state can be of use: namely, finding the man for the job and finding the job for the man.

It is fair to say that an employer is primarily more interested in the former aspect. If one man is more physically suited to a particular job than another man then, other things being equal, the first man is obviously the "man for the job." I fail to see how this can be considered to be discrimination any more than academic qualifications or innate ability. Furthermore, if a man's application for a certain post is rejected " on medical grounds" then he may well be encouraged to apply for a position more suited to his state of health, i.e. " the job for the man."

I hasten to add that I have every sympathy with Dr. Todd in respect of the individual case quoted. Arbitrary line-drawing in such a variable physiological phenomenon as the level of arterial blood pressure is, in the context of general physical fitness, a practice to be deprecated.-I am, etc.,

PETER M. BRown.

Port Medical Service,

National Dock Labour Board.

Liverpool 2.

\section{Avulsion of the Upper Limb}

SIR,-Avulsion of the upper limb is a rare injury. During the last twenty years only 15 cases have been recorded. ${ }^{1-4}$ In every case the injury has been the result of the hand or lower arm being trapped in moving machinery which produces a violent torsion of the arm. The level of avulsion would appear to depend on the degree of resistance to this torsion drag. During the last ten years three cases of avulsion of the upper limb have been treated in the casualty department of Kaplan Hospital.

A 43-year-old man was working in a sandpit on a building construction site. His right arm was caught in the machinery used to lift sand and other construction material up to the level of the building work. The patient was admitted to hospital about one hour after the injury fully conscious but suffering from shock with blood pressure 100/55. He had complete avulsion of the right arm in the region of the shoulder joint. The scapula and the clavicle could be seen in the depths of a large, ragged wound. At operation, after transfusion, the main nerves of the brachial plexus were seen to have been avulsed just below the clavicle. The wound was closed over drainage and healed with surprising speed, the general condition rapidly returning to normal.

The second case was a 24-year-old man whose left hand and forearm had been caught in a wire rope being wound on a revolving drum. The patient had been thrown six or seven feet in the air and fell on his head. At the time of admission he was not fully conscious and appeared to have a degree of cerebral concussion. He had multiple lacerated wounds on his head, forehead, and nose. Avulsion of the left arm had taken place through the upper third of the humerus, the end of which bone was protruding through the soft tissues. Blood pressure was $90 / 50$. He was resuscitated with $800 \mathrm{ml}$. of blood and operated upon shortly afterwards. All damaged muscle and skin were excised. The contaminated lower end of the stump of humerus was removed. At operation, which took place after transfusion, the axillary vessels were found to be in spasm and not bleeding. They were ligated. The wound healed by first intention, and he had no subsequent disabilities from the head injury. (See Figs 1-3.)

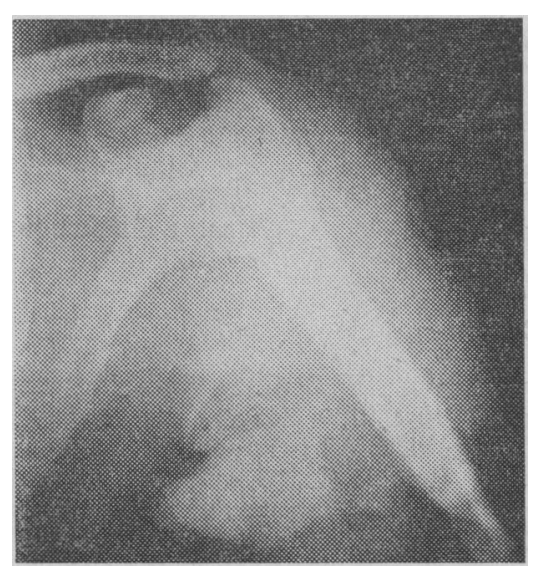

FIG. 1.-On admission.

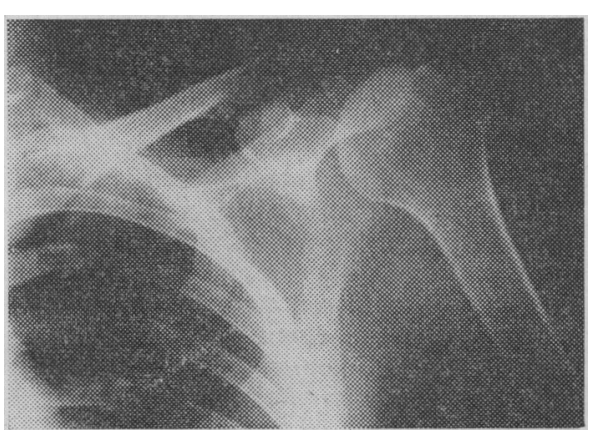

FIG. 2.-After healing.

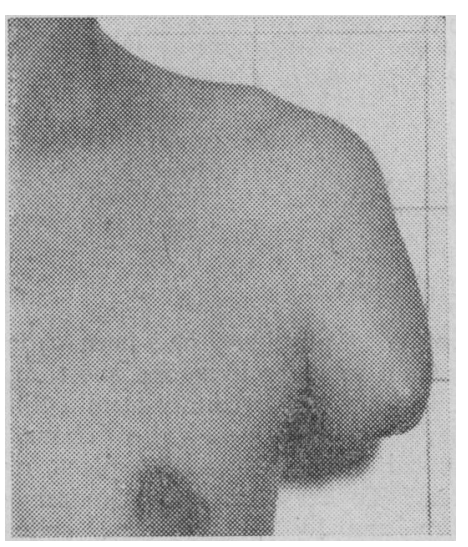

FIG. 3.-Final result.
The third case was a 21-year-old man who was directing a thick cable which was passing through his hands to a revolving drum at an estimated speed of two and a half kilometres an hour. The patient was using special thick gloves for this work. His left glove was suddenly caught by a defect in the cable. He was unable to remove his hand from the glove before the whole limb was caught in the revolving drum and thus avulsed. He was at once taken to the small local hospital, where the axillary artery was ligated and blood transfusion given before he was transferred to Kaplan Hospital. The left arm had been totally avulsed through the upper quarter of the humerus. Because of skin loss in this case, it was not possible to leave a stump of the upper arm. The remaining small fragment of the humerus was, therefore, brought down against the chest and the skin wound closed over the bone. The usual antibiotic treatment was given. The patient's general condition improved gradually and his wound healed by first intention.

In each of these three cases the avulsed limbs did not reach hospital. It was therefore not possible to even consider the reattachment of the limbs as has been reported elsewhere. In all cases the injury produced a moderate degree of shock. One patient was unconscious at the time of admission because of head injury. The significant feature reported by all those who have written about this injury is the very small degree of bleeding. The arteries go into spasm owing to the violent injury and torsion effect, and it is this which undoubtedly saves life after this injury. All the wounds were large and grossly contaminated, with considerable muscle damage. After appropriate and extensive surgical excision, drainage, and the use of antibiotics, all three cases healed by first intention.

In spite of the severity of this injury it would appear that the patient usually survives. With the increasing use of machinery and mechanization, it seems likely that this type of injury may become more common. In most countries there are rigid safety factors for workers with dangerous machinery, but too often such safety regulations are ignored by those working with the machinery.-I am, etc.

I. BARZIANO.

Orthopaedic Department Rehovoth, Israe

\section{REFERENCES}

1 Peatfield, G. R. C., Brit. med. F., 1950, 1, 821. 2 Pracy, D. S., Brit. med. F., 1958, 2, 1578.
Valentinovich, E. M., Khirurgiya (Mosk.), 1961,

Wax, W. V., Amer. F. Surg., 1953, 86, 728 College of Psychiatrists should include among their numbers some general physicians who have special experience of physical illness as 